\title{
RESEARCH
}

Open Access

\section{Predictors of pacing induced left ventricular dysfunction and cardiomyopathy assessed by three-dimensional echocardiography and speckle tracking strain}

\author{
Moustafa Dawood ${ }^{*}$ (D), Eman Elsharkawy, Mohamed Ayman Abdel-Hay and Moustafa Nawar
}

\begin{abstract}
Background: Long-term RV pacing leads to ventricular dyssynchrony, in the form of LBBB-like morphology, with subsequent detrimental effects on LV structure and function. Three-dimensional echocardiography allowed early detection of volumetric changes associated with PICMP and provided more accurate assessment of mechanical dyssynchrony. Speckle tracking strain is able to identify LV dysfunction even before any reduction in LVEF. Our aim was to study pacing effects on LV function and hemodynamics using 3D echo and speckle tracking strain.

Results: This was a prospective study of 175 consecutive patients without structural heart disease (LVEF > 50\%) presented for permanent pacing. Full-volume 3D echocardiography done before implantation, 1 week, and 6 months together with GLS. Patients were followed for 6 months to detect incidence of PIVD (defined as reduction in LVEF > 10\% but still above 50\%) and PICMP (defined as decrease in LVEF by $10 \%$ from baseline in absence of other known causes of cardiomyopathy resulting in EF < 50\%). PIVD and PICMP predictors and risk factors were analyzed. Only 50 patients met study criteria. Twenty-five (50\%) patients developed LV systolic dysfunction; of these, 19 (38\%) developed PIVD and 6 (12\%) developed PICMP. Pre-implantation GLS was significantly lower in the 6 patients who subsequently developed PICMP, compared to those who developed PIVD and the preserved EF group (mean GLS -15.50 vs. $-21.0,-20.0$ respectively; $p=0.005,0.033$, respectively). At 1 week, GLS was significantly lower in the 25 patients who subsequently developed PIVD, compared to those who did not (GLS - 13.0 vs. - 18.0, respectively; $p=0.002$ ). A reduction of baseline GLS by $15 \%$ or more at 1 week was associated with the development of PIVD and PICMP $(p=<0.001)$. A wider native QRS complex was associated with PIVD and PICMP ( $p=0.008,0.018$, respectively). The other predictors were found non-significant.
\end{abstract}

Conclusion: PICMP may be more common than previously reported and it may occur shortly after implantation. Pre-implantation GLS is a sensitive parameter for PICMP. One-week GLS, pre-implantation QRS complex width are early predictors for PICMP and PIVD before any reduction in EF.

Keywords: Pacing induced LV dysfunction, Pacing-induced cardiomyopathy, 3D echocardiography, Global longitudinal strain, Cardiac pacemakers, Pacing hemodynamics

\footnotetext{
* Correspondence: moustafadawood@yahoo.com

Cardiology and Angiology Department, Alexandria Faculty of Medicine,

Alexandria 21568, Egypt
}

\section{Springer Open}

(c) The Author(s). 2021 Open Access This article is licensed under a Creative Commons Attribution 4.0 International License which permits use, sharing, adaptation, distribution and reproduction in any medium or format, as long as you give appropriate credit to the original author(s) and the source, provide a link to the Creative Commons licence, and indicate if changes were made. The images or other third party material in this article are included in the article's Creative Commons licence, unless indicated otherwise in a credit line to the material. If material is not included in the article's Creative Commons licence and your intended use is not permitted by statutory regulation or exceeds the permitted use, you will need to obtain permission directly from the copyright holder. To view a copy of this licence, visit http://creativecommons.org/licenses/by/4.0/. 


\section{Background}

During recent years, there was a focus on the negative effects associated with long-term RV pacing. The DAVI D Trial [1] and a sub-analysis of the MADIT II [2] were one of the first trials to report these changes in HF patients. It was shown in both experimental and clinical studies that RV pacing may lead to ventricular dyssynchrony, similar to that of LBBB with subsequent abnormal electrical and mechanical activation of the ventricles [3]. This results in changes in cardiac metabolism, perfusion, hemodynamics, and mechanical function $[4,5]$. Long-term RV pacing may also result in structural changes and LV remodeling [6]. In addition, it has been suggested that the presence of mechanical dyssynchrony after long-term RV apical pacing is associated with reduced LV systolic function and deterioration in functional capacity [7] and in some cases adverse clinical outcomes such as atrial fibrillation, heart failure, and death [8-10]. However, in daily clinical practice, not all patients who receive RV apical pacing will experience these adverse events [11]. Initial bi-ventricular pacing prevents these complications but it cannot be applied in all cases due to its high cost and related complications.

\section{Aim of the work}

To detect the incidence of PIVD and PICMP over 6 months post-pacing and to study the predictors and risk factors for their development.

\section{Methods}

The study was approved by the ethics committee at our faculty of medicine. All patients provided written informed consent. Patients' recruitment started from October 2017 to August 2018. During this period, 175 consecutive patients presented to our university hospitals for device implantation. Only 50 patients met the inclusion criteria and were included.

The exclusion criteria included the presence of more than mild valvular heart disease, left ventricular ejection fraction less than 50\%, presence of ischemic heart disease, recent cardiac surgery during the last 3 months before enrollment. Patients with poor echo windows, patients with slow atrial fibrillation, or other types of arrhythmia that can affect LV function, debilitated or cancer patients with expected survival less than 1 year and patients with previously implanted devices were excluded. Of 175 patients, 125 patients were excluded. Sixty-five patients were presented with reduced LV systolic function for cardiac resynchronization therapy. Sixteen patients were assigned for ICD devices as primary or secondary prevention with no indication for permanent pacing. Twenty-two patients had previously implanted devices at the elective replacement period and were scheduled for battery replacement. Seven patients were subjected to reoperation due to device-related complications (4 with twiddler syndrome and 3 for device extraction due to bloodstream or device-related infection). Eight patients presented with slow atrial fibrillation or SSS. Two patients had poor echo views and four patients had significant valvular heart disease. One patient died before the second follow-up. The remaining 50 patients were assigned to have singlechamber (27 patients) or dual-chamber pacemaker (23 patients).

\section{Patient characteristics}

Patient's demographic data, medical comorbidities and indications for pacing were collected and revised $24 \mathrm{~h}$ before pacing. Patients' age ranged from 12 to 97 years with mean age of $63.12 \pm 16.85$ years. According to gender, 27 patients were males (54\%). In addition, 13 patients $(26.0 \%)$ were diabetics, and 21 patients (42.0\%) were hypertensive. All patients had structurally normal heart confirmed by echocardiography.

\section{Data collection: 2D, 3D echo full volume acquisition, and GLS analysis}

A standard 12 lead ECG was done before pacing. ECG data were collected and recorded including native QRS width, axis, heart rate, degree of heart block, and presence of LBBB or RBBB-like morphology. BBB was defined according to the standard criteria. All ECG parameters were rechecked and recorded immediately after pacing and at 6 months.

A full 2D echocardiographic study was done to exclude patients with significant valvular heart disease, IHD or reduced LVEF. A 3D full volume acquisition of the left ventricle was done using the Philips Medical iE33 echocardiography system with X5-1 transthoracic probe. For 3D full volume acquisitions, ensuring adequate frame rate, packet size and capture of the full cardiac cycle, the system obtained a $30^{\circ}$ _ $30^{\circ}$ pyramid over 4 to 6 alternate gated cardiac cycles. The resulting dynamic 3D full volume sector was reviewed and navigated through immediately to ensure all areas of interest have been captured. All the acquisitions were ECG gated and patients were told to hold their breath during acquisition to avoid stitch artifacts. After completion of the study, 3D acquired data were transferred to Q-lab 10 for off-line analysis. In order to calculate LV volumes and $\mathrm{EF}$, both the long and short LV axis were adjusted to get maximum LV dimensions and to avoid foreshortening then five landmarks were chosen to initiate edge detection by semi-automated quantification software. Four landmarks were placed at the mitral annulus and the fifth was placed at the apex in apical four or apical two views. The software delineated LV boundaries automatically, but it allowed manual modifications to include or 
exclude any part for more accurate adjustment of LV borders. After borders' delineation, the software automatically calculated EDV, ESV, SV, COP, and EF.

For GLS calculation, 2D gated acquisition of the apical views (apical four, two, and three) were done according to the standard techniques. Patients were told to hold their breath during acquisition and foreshortening was avoided. GLS was calculated for each of the three apical views then mean GLS was calculated automatically. Three-dimensional echo and GLS acquisition and analysis were repeated at 1 week and 6 months after implantation to detect the incidence of PIVD (defined as a reduction in LVEF $>10$ percentage points but still above 50\%) and PICMP (defined as a decrease in LVEF by 10 percentage points from baseline resulting in $\mathrm{EF}<50 \%$ (in the absence of other known causes of cardiomyopathy.

\section{Pacemaker implantation and programming}

Implantation was performed according to the operator's usual practice. The study population was assigned to receive a single-chamber ventricular pacemaker (23 patients) or a dual-chamber pacemaker (27 patients). Since all the previously mentioned studies showed no difference in RV lead position [12, 13], the decision was left to the operator to position the lead according to his preference. Most of the cases had RV lead in an apical position because it was easier and more readily accessible by our operators. RV apex was selected as the site of RV lead implantation in 44 candidates. The remaining six patients had septal pacing, confirmed by the post-pacing ECG axis. Patients with single chamber pacemakers were programmed to VVIR mode while those with dual-chamber pacing were programmed to DDDR mode. Rate responsive mode was selected as it resulted in better outcomes regarding patient quality of life and exercise tolerance [14]. Suggested settings for single and dual-chamber pacemakers were lower and upper rate limits of 60 beats per minute and 130 beats per minute, respectively. In order to maximize the contribution of the atrial kick to SV in the DDDR group, dynamic AV time delay [15] was selected with resting paced/sensed AV time delay adjusted to 200/ $150 \mathrm{~ms}[15,16]$. Pacing lowering strategies were applied to reduce ventricular pacing percentage (VP \%). Patients were recruited 7-10 days post-pacing and after 6 months. Device interrogation was done to check the adjusted pacing parameters and acquire ventricular pacing percentage. Also, 3D echo and GLS were calculated at follow up visits as described before.

\section{Statistical analysis}

The database was maintained and analyzed by an independent data-management group. To assess the distribution of the data derived from this study, we calculated the standardized skewness and kurtosis of each of the variables. Normally distributed values were expressed as mean and skewed values as the median (interquartile range). Paired two-tailed group comparisons were made with Student's $t$ (parametric) or Wilcoxon signed-rank (non-parametric) tests as appropriate. $p$ values of less than 0.05 were regarded as significant.

\section{Results}

Device interrogation showed high ventricular pacing percentage at 6 months follow-up. All the patients were pacemaker dependent with mean VP\% of $92 \pm 3 \%$. There were no significant differences between both groups before implantation regarding the following parameters (ESV, EDV, SV, COP, EF, and GLS) (Table 1).

Only 50 patients met the study criteria; of them, 25 patients $(50 \%)$ showed a decline in post-pacing EF by $10 \%$ or more compared to baseline by the end of the study. Sub-group analysis divided them into 19 patients (38\%) with PIVD and 6 patients (12\%) developed PICMP (Fig. 1). In the PIVD group, mean EF\% dropped from 75.8 to $57.8 \%$ at 6 months. In the PICMP group, mean EF dropped from $68.3 \%$ to $36 \%$. Also, PICMP group showed marked increase in ESV immediately postpacing and at 6 months $(p=0.003,<0.001$, respectively) with subsequent reduction in SV at 6 months $(p=$ 0.032) (Table 1, Fig. 1).

All the studied parameters were analyzed at a level of two main groups (preserved EF group and group with LV dysfunction) then repeated in a sub-group analysis between PIVD and PICMP groups. Low GLS was associated with further deterioration in LV systolic function. Pre-implantation, GLS was significantly lower in the six patients who subsequently developed PICMP, compared to those who developed PIVD and the preserved EF group (mean GLS - 15.50 vs. - 21.0, - 20.0, respectively; $p=0.005,0.033$, respectively), (supplementary PICMP cases 1 and 2). At 1 week, GLS was significantly lower in the 25 patients who subsequently developed LV systolic dysfunction, compared to those who did not (GLS 13.0 vs. -18.0 respectively; $p=0.002$ ) (Table 1 , Fig. 2, supplements PIVD case 1). A reduction of baseline GLS by $15 \%$ or more at 1 week was associated with the development of PIVD and PICMP ( $p=<0.001)$ (Table 2). A wider native QRS complex was associated with the development of PIVD and PICMP $(p=0.008,0.018$, respectively). The rest of the studied parameters were found not significant (Tables 3 and 4).

\section{Discussion}

Our study detected a surprisingly high incidence of pacing-induced LV systolic dysfunction. In addition, it showed that it occurred shortly after implantation. Preimplantation GLS is a sensitive parameter for PICMP. One-week GLS, pre-implantation QRS complex width 
Table 1 Comparison between the three studied groups according to echo parameters and GLS

\begin{tabular}{|c|c|c|c|c|c|}
\hline \multirow{3}{*}{$\begin{array}{l}\text { Predisposing } \\
\text { factors }\end{array}$} & \multirow{2}{*}{$\begin{array}{l}\text { No decline in LVEF } \\
(n=25)\end{array}$} & \multicolumn{2}{|l|}{ Decline in LVEF } & \multirow[t]{3}{*}{$x^{2}$} & \multirow[t]{3}{*}{${ }^{M C} p$} \\
\hline & & $\begin{array}{l}\text { PIVD } \\
(n=19)\end{array}$ & $\operatorname{PICMP}(n=6)$ & & \\
\hline & No. & No. & No. & & \\
\hline \multicolumn{6}{|l|}{ EF\% } \\
\hline Pre-pacing & $68.0 \pm 6.84$ & $75.79 \pm 5.27$ & $68.33 \pm 9.83$ & $7.856^{*}$ & $0.001^{*}$ \\
\hline Post-pacing (at 7 days) & $64.16 \pm 7.64$ & $67.74 \pm 8.19$ & $47.83 \pm 6.79$ & $15.105^{*}$ & $<0.001^{*}$ \\
\hline Post-pacing (at 6 months) & $61.76 \pm 6.22$ & $57.79 \pm 4.38$ & $36.0 \pm 10.79$ & $40.815^{*}$ & $<0.001^{*}$ \\
\hline \multicolumn{6}{|l|}{ ESV (ml) } \\
\hline Pre-pacing & $34.12 \pm 11.94$ & $26.53 \pm 8.52$ & $34.0 \pm 10.08$ & 3.031 & 0.058 \\
\hline Post-pacing (at 7 days) & $30.84 \pm 10.59$ & $28.21 \pm 12.09$ & $46.33 \pm 5.82$ & 6.562 & $0.003^{*}$ \\
\hline Post-pacing (at 6 months) & $34.36 \pm 9.81$ & $37.53 \pm 11.55$ & $73.50 \pm 35.49$ & $16.313^{*}$ & $<0.001^{*}$ \\
\hline \multicolumn{6}{|l|}{$\mathrm{EDV}(\mathrm{ml})$} \\
\hline Pre-pacing & $104.8 \pm 25.81$ & $104.7 \pm 23.58$ & $111.3 \pm 25.87$ & 0.342 & 0.843 \\
\hline Post-pacing (at 7 days) & $89.40 \pm 22.49$ & $89.26 \pm 22.92$ & $93.67 \pm 24.48$ & 0.081 & 0.960 \\
\hline Post-pacing (at 6 months) & $90.84 \pm 22.22$ & $89.0 \pm 24.47$ & $111.8 \pm 40.35$ & 1.222 & 0.543 \\
\hline \multicolumn{6}{|l|}{$\mathrm{SV}$ (ml) } \\
\hline Pre-pacing & $70.64 \pm 17.70$ & $77.11 \pm 17.32$ & $77.33 \pm 27.52$ & 0.748 & 0.479 \\
\hline Post-pacing (at 7 days) & $58.48 \pm 16.12$ & $61.05 \pm 17.22$ & $47.33 \pm 19.36$ & 1.512 & 0.231 \\
\hline Post-pacing (at 6 months) & $56.44 \pm 15.36$ & $51.68 \pm 14.29$ & $38.33 \pm 13.09$ & 3.700 & 0.032 \\
\hline \multicolumn{6}{|l|}{ COP (L/min) } \\
\hline Pre-pacing & $2.96 \pm 0.87$ & $3.32 \pm 1.05$ & $2.63 \pm 0.74$ & 3.722 & 0.156 \\
\hline Post-pacing (at 7 days) & $3.90 \pm 0.95$ & $4.39 \pm 1.43$ & $3.60 \pm 1.21$ & 1.715 & 0.424 \\
\hline Post-pacing (at 6 months) & $3.70 \pm 0.92$ & $3.72 \pm 1.38$ & $2.72 \pm 0.69$ & 4.754 & 0.093 \\
\hline \multicolumn{6}{|l|}{ GLS\% } \\
\hline Pre-pacing & $-19.52 \pm 3.62$ & $-20.79 \pm 3.43$ & $-15.50 \pm 2.07$ & $5.482^{*}$ & $0.007^{*}$ \\
\hline Post-pacing (at 7 days) & $-16.80 \pm 3.59$ & $-14.21 \pm 4.21$ & $-10.17 \pm 1.17$ & 8.609 & $0.001^{*}$ \\
\hline Post-pacing (at 6 months) & $-15.40 \pm 3.46$ & $-12.32 \pm 4.60$ & $-8.0 \pm 2.76$ & 9.888 & $<0.001^{*}$ \\
\hline
\end{tabular}

*Statistically significant at $p \leq 0.05$

are early predictors for PICMP and PIVD before any reduction in EF. Pre-implantation QRS complex width may predict the development of PICMP and PIVD.

PICMP is an important clinical problem in day-to-day practice. It was reported to develop from the first month and up to 15 years after pacemaker implantation [17]. This topic has been extensively studied previously. However, the data on the prevalence of PICMP after longterm RV pacing varies significantly. In part, this can be explained by the heterogeneity in determining the exact prevalence of PICMP:

- First, the lack of globally unified criteria of PICMP. Some studies depended on imaging modalities only for diagnosis while others added clinical endpoints. Khurshid et al. [18] defined PICMP as a decrease of $50 \%$ or more in LVEF resulting in value less than $50 \%$. PICMP incidence as defined by an EF less than $45 \%$ was reported to be $9 \%$ after the first year [19].
Zhang et al. [20] reported new-onset heart failure in $26 \%$ prevalence of PICMP after 10 years. Kiehl et al. [21] reported a $12.3 \%$ incidence over 4.3 years. In other studies, lesser degrees of pacing-induced LV dysfunction (PIVD) have also been observed in up to two-thirds of patients with normal baseline LV function. They defined pacing-induced LV dysfunction (PIVD) as a reduction in LV ejection fraction (LVEF) by 5 percentage points or more at 12 months) [22, 23].

- Second, PM patients often suffer from comorbidities that also cause adverse LV remodeling (e.g., IHD). A prospective study with a median follow-up of 7.8 years on 79 patients reported that (26.0\%) developed new-onset HF after RV apical pacing. It has been shown that the presence of IHD was an independent risk factor for developing PICM P. A supply demand mismatch was the suggested explanation. Pacing at higher rates than the patient 


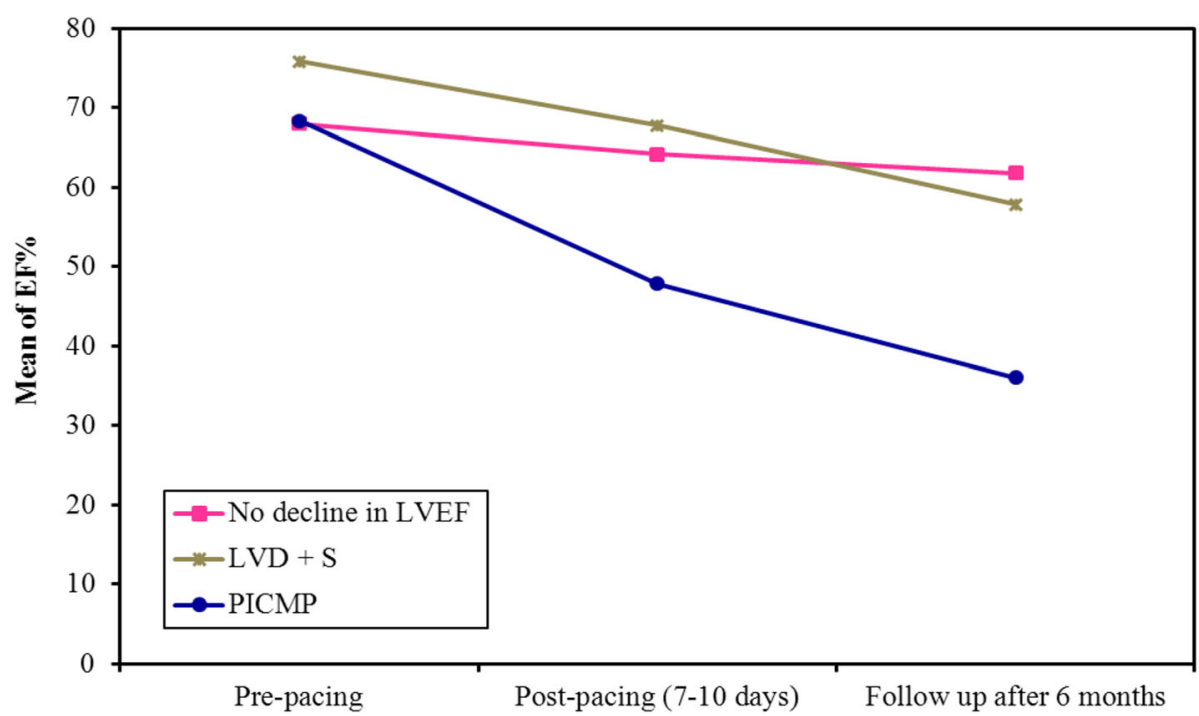

Fig. 1 Comparison between the different periods in each of the three studied groups (no decline in LVEF, PIVD, PICMP)

pre-implantation rate increases myocardial work, oxygen demand and creates relative ischemia in patients with diseased coronaries [20].

- The third reason is that not all PM patients require continuous RV pacing.

Our study tried to overcome the drawbacks of the previously reported studies and to start from they ended. Using a clinical endpoint or reporting the reduction in LVEF is often a late phenomenon. Once LVEF is decreased, despite intervention there is a failure of recovery of systolic function in up to $58 \%$ of patients [24]. This created the need for an imaging modality that is relatively inexpensive and that can pick up early PICMP.

The study was designed to implement more sensitive tools such as 3D echo and strain analysis for earlier and more accurate detection of pacing-induced negative effects on LV structure and function. We excluded patients with underlying arrhythmia, ischemic, valvular heart disease, or other potential confounding factors. Only pacing dependent patients due to advanced heart block were included.

After 6 months, pacing resulted in a significant drop in EF. This was due to pacing-induced remodeling of LV structure resulting in the expansion of LV volumes, mainly the ESV. A reduction in GLS was a predictor for further deterioration in LV systolic function. Pre-implantation, GLS was significantly lower in the six patients who subsequently developed PICMP, compared to those who developed PIVD and the preserved EF group (mean GLS 15.50 vs. - 21.0, - 20.0, respectively; $p=0.005$, 0.033 , respectively). At 1 week, GLS was significantly lower in the 25 patients who subsequently developed LV systolic dysfunction, compared to those who did not (GLS - 13.0 vs. -18.0 , respectively; $p=0.002$ ).

There is a growing number of literatures highlighting the detrimental effects of pacing on speckle tracking strain. Victoria Delgado et al. [25] studied the acute effects of RV apical pacing on LV Synchrony and Mechanics in 25 patients with structurally normal. During RV apical pacing, a more dyssynchronous LV contraction was observed together with an impairment in LV longitudinal shortening and in LV twist. In a prospective study of 36 patients with a baseline EF of more than $45 \%$ who received a permanent pacemaker followed for 6 months. A significant decrease in LV global longitudinal strain was noted in $23(63.9 \%)$ patients by 6 months. In seven of these patients, there was a significant decrease in global longitudinal strain $24 \mathrm{~h}$ after implantation [24]. In a recent study conducted in 2017, 93 patients were followed for $60 \pm 47$ months. They found that lower LV peak GLS was the only independent predictor for LV dyssynchrony and patients with lower GLS value could be at risk of PICMP [26].

The previously published studies did not link DM or HTN to the development of PICMP. Kim et al. [27] reported abnormal post-pacing QRS axis to be associated with PICMP. Another study showed that male gender, wide native QRS complex and lower baseline LVEF to be predictors of PICMP over a period of 3.3 years [28] UK-PACE Trial [29] showed no difference between single- and dual-chamber pacemakers regarding the rates of atrial fibrillation, heart failure, or a composite of stroke, transient ischemic 


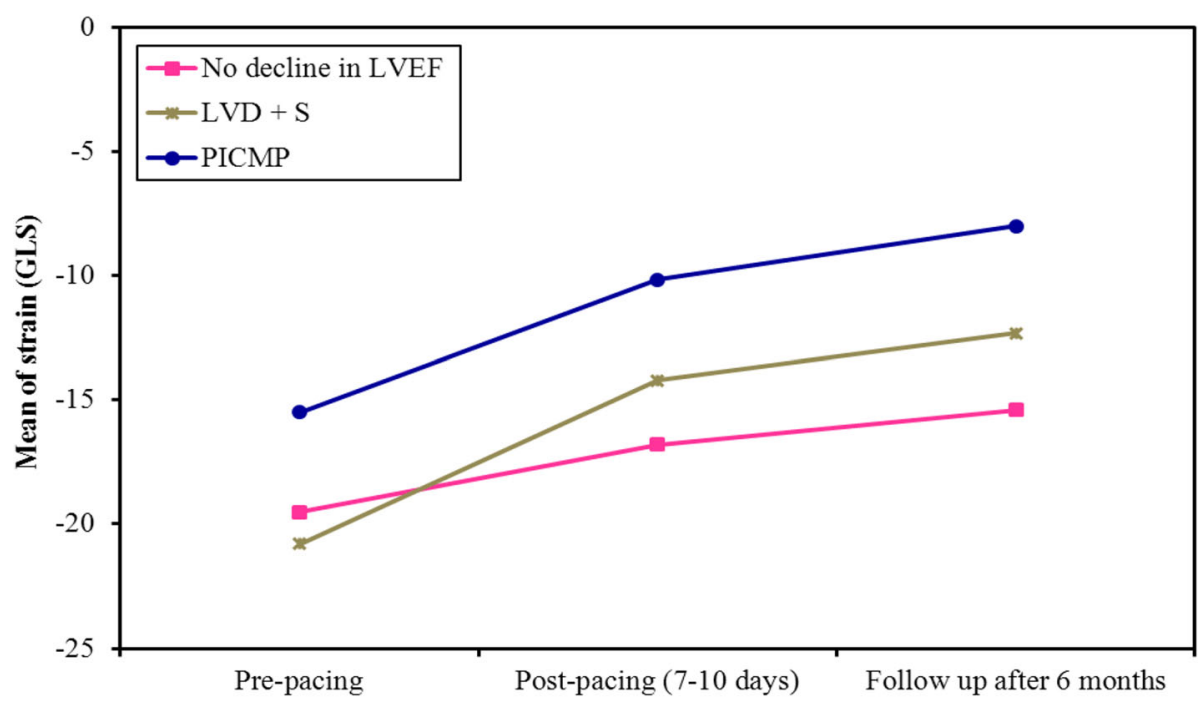

Fig. 2 Comparison between the three studied groups according to changes in Global Longitudinal Strain (GLS) in each group

attack, or other thromboembolism. We studied possible risk factors for the development of PICMP. Only the width of the baseline QRS complex was found significant. This was probably due to the small sample size and short duration of follow-up. We did not include a clinical point to the trial. We divided the affected patients into two groups, PIVD and PICMP, for earlier detection. This also allowed better studying of risk factors for developing cardiomyopathy over a short- and long-term basis. Signifying the importance of baseline and post-pacing GLS as predictors for PICMP and PIVD was the main outcome of our study. Further trials with larger sample sizes and longer follow-up periods are required to validate our results and to introduce GLS in the routine follow-up of pacemaker patients.

\section{Study limitations}

Our study had a number of limitations; the most important was the small sample size. The study duration was relatively short. We believe that higher incidence of pacing-induced LV dysfunction could be expected with longer follow up. In addition, a large number of patients received single-chamber pacing despite being in sinus rhythm. In our center, pacemakers are provided through different sources. Health assurances provide dual-chamber pacemakers for its patients if indicated. Uncovered patients are provided singlechamber devices through donations or by emergency decisions on the expense of the state as a lifesaving act. Dual-chamber pacemakers are not available in the donation sector due to financial aspects. This allows us to save a greater number of patients.

\section{Conclusion}

Pacing-induced negative effects may be more common than previously reported and may occur shortly after implantation. This rise in its incidence is due to the application of more sensitive tools like 3D echocardiography and speckle tracking strain. Pre-implantation GLS is a sensitive parameter for the development of PICMP. One-week GLS is an early predictor for the

Table 2 Comparison between the two studied groups according STS reduction percentage at 1-week follow-up visit

\begin{tabular}{|c|c|c|c|c|c|c|c|c|}
\hline & \multicolumn{2}{|c|}{$\begin{array}{l}\text { Total } \\
(n=50)\end{array}$} & \multicolumn{2}{|c|}{ No decline in $\operatorname{LVEF}(n=25)$} & \multicolumn{2}{|c|}{ Decline in $\operatorname{LVEF}(n=25)$} & \multirow[t]{2}{*}{ Test of sig. } & \multirow[t]{2}{*}{$p$} \\
\hline & No. & $\%$ & No. & $\%$ & No. & $\%$ & & \\
\hline \multicolumn{9}{|c|}{$\%$ (7 days) } \\
\hline$\leq 15$ & 23 & 46.0 & 22 & 88.0 & 1 & 4.0 & $x^{2}=29.639^{*}$ & $<0.001^{*}$ \\
\hline$>15$ & 27 & 54.0 & 3 & 12.0 & 24 & 96.0 & & \\
\hline
\end{tabular}

$x^{2}$ Chi-square test

${ }^{*}$ Statistically significant at $p \leq 0.05$ 
Table 3 Comparison between the two studied groups according to risk factors

\begin{tabular}{|c|c|c|c|c|c|c|c|c|}
\hline \multirow[t]{2}{*}{$\begin{array}{l}\text { Predisposing } \\
\text { factors }\end{array}$} & \multicolumn{2}{|c|}{$\begin{array}{l}\text { Total } \\
(n=50)\end{array}$} & \multicolumn{2}{|c|}{$\begin{array}{l}\text { No decline in LVEF } \\
(n=25)\end{array}$} & \multicolumn{2}{|c|}{$\begin{array}{l}\text { Decline in LVEF } \\
(n=25)\end{array}$} & \multirow[t]{2}{*}{$x^{2}$} & \multirow[t]{2}{*}{${ }^{M C_{p}}$} \\
\hline & No. & $\%$ & No. & $\%$ & No. & $\%$ & & \\
\hline Age (years) & \multicolumn{2}{|c|}{$63.12 \pm 16.85$} & \multicolumn{2}{|c|}{$67.20 \pm 18.54$} & \multicolumn{2}{|c|}{$59.04 \pm 14.18$} & & \\
\hline Mean \pm SD & & & & & & & 202.00 & $0.032^{*}$ \\
\hline \multicolumn{9}{|l|}{ Sex } \\
\hline Male & 27 & 54.0 & 14 & 56.0 & 13 & 52.0 & 0.081 & 0.777 \\
\hline Female & 23 & 46.0 & 11 & 44.0 & 12 & 48.0 & & \\
\hline DM & 13 & 26.0 & 7 & 28.0 & 6 & 24.0 & 0.104 & 0.747 \\
\hline HTN & 21 & 42.0 & 14 & 56.0 & 7 & 28.0 & $4.023^{*}$ & $0.045^{*}$ \\
\hline \multicolumn{9}{|l|}{ Device type } \\
\hline $\mathrm{Wl}$ & 27 & 54.0 & 15 & 60.0 & 12 & 48.0 & 0.725 & 0.395 \\
\hline DDD & 23 & 46.0 & 10 & 40.0 & 13 & 52.0 & & \\
\hline \multicolumn{9}{|l|}{ Lead site } \\
\hline RVA & 44 & 88.0 & 22 & 88.0 & 22 & 83.0 & 0.00 & 1.000 \\
\hline RVS & 6 & 12.0 & 3 & 12.0 & 3 & 12.0 & & \\
\hline \multicolumn{9}{|c|}{ Pre-existing BBB } \\
\hline No BBB & 22 & 44.0 & 15 & 60.0 & 7 & 28.0 & & \\
\hline RBBB & 19 & 38.0 & 7 & 28.0 & 12 & 48.0 & 5.107 & 0.083 \\
\hline LBBB & 9 & 18.0 & 3 & 12.0 & 6 & 24.0 & & \\
\hline \multicolumn{9}{|l|}{ QRS axis } \\
\hline N & 8 & 16.0 & 4 & 16.0 & 4 & 16.0 & & \\
\hline$L F$ & 38 & 76.0 & 20 & 80.0 & 18 & 72.0 & 1.514 & 0.883 \\
\hline RT & 4 & 8.0 & 1 & 4.0 & 3 & 12.0 & & \\
\hline \multicolumn{9}{|l|}{ QRS width } \\
\hline \multicolumn{9}{|l|}{ Pre-pacing } \\
\hline Mean \pm SD & \multicolumn{2}{|c|}{$116.8 \pm 32.27$} & \multicolumn{2}{|c|}{$104.6 \pm 27.99$} & \multicolumn{2}{|c|}{$129.0 \pm 32.15$} & $178.00^{*}$ & $0.008^{*}$ \\
\hline \multicolumn{9}{|l|}{ Post-pacing } \\
\hline Mean \pm SD & \multicolumn{2}{|c|}{$151.7 \pm 21.91$} & \multicolumn{2}{|c|}{$148.6 \pm 22.98$} & \multicolumn{2}{|c|}{$154.8 \pm 20.79$} & 273.00 & 0.436 \\
\hline \multicolumn{9}{|l|}{ VP\% } \\
\hline \multicolumn{9}{|l|}{7 days } \\
\hline Mean \pm SD & \multicolumn{2}{|c|}{$84.34 \pm 24.83$} & 83.40 & & 85.27 & & 285.50 & 0.588 \\
\hline 6 months & & & & & & & & \\
\hline Mean \pm SD & 89.26 & & 86.80 & & 91.72 & & 289.00 & 0.601 \\
\hline Pacing thresh & & & & & & & & \\
\hline 7 days & & & & & & & & \\
\hline Mean \pm SD & 0.57 & & 0.57 & & 0.57 & & 267.50 & 0.328 \\
\hline 6 months & & & & & & & & \\
\hline Mean \pm SD & 0.88 & & 0.85 & & 0.90 & & 306.50 & 0.902 \\
\hline
\end{tabular}


Table 4 Comparison between the three studied groups according to risk factors

\begin{tabular}{|c|c|c|c|c|c|c|c|c|}
\hline \multirow{3}{*}{$\begin{array}{l}\text { Predisposing } \\
\text { factors }\end{array}$} & \multirow{2}{*}{\multicolumn{2}{|c|}{$\begin{array}{l}\text { No decline in LVEF } \\
(n=25)\end{array}$}} & \multicolumn{4}{|c|}{ Decline in LVEF } & \multirow[t]{3}{*}{$x^{2}$} & \multirow[t]{3}{*}{$M C_{p}$} \\
\hline & & & \multicolumn{2}{|c|}{$\begin{array}{l}\text { PIVD } \\
(n=19)\end{array}$} & \multicolumn{2}{|c|}{$\operatorname{PICMP}(n=6)$} & & \\
\hline & No. & $\%$ & No. & $\%$ & No. & $\%$ & & \\
\hline Age (years) & \multicolumn{2}{|c|}{$67.20 \pm 18.54$} & \multicolumn{2}{|c|}{$57.11 \pm 14.77$} & \multicolumn{2}{|c|}{$65.17 \pm 10.94$} & & \\
\hline Mean \pm SD & & & & & & & 5.565 & 0.062 \\
\hline \multicolumn{9}{|l|}{ Sex } \\
\hline Male & 14 & 56.0 & 9 & 47.4 & 4 & 66.7 & 0.790 & 0.786 \\
\hline Female & 11 & 44.0 & 10 & 52.6 & 2 & 33.3 & & \\
\hline DM & 7 & 28.0 & 3 & 15.8 & 3 & 50.0 & 2.858 & 0.231 \\
\hline HTN & 14 & 56.0 & 4 & 21.1 & 3 & 50.0 & 5.650 & 0.060 \\
\hline \multicolumn{9}{|l|}{ Device type } \\
\hline $\mathrm{Wl}$ & 15 & 60.0 & 10 & 52.6 & 2 & 33.3 & 1.410 & 0.517 \\
\hline DDD & 10 & 40.0 & 9 & 47.4 & 4 & 66.7 & & \\
\hline \multicolumn{9}{|l|}{ Lead site } \\
\hline RVA & 22 & 88.0 & 17 & 89.5 & 5 & 83.3 & 0.592 & 1.000 \\
\hline RVS & 3 & 12.0 & 2 & 10.5 & 1 & 16.7 & & \\
\hline \multicolumn{9}{|c|}{ Pre-existing BBB } \\
\hline No BBB & 15 & 60.0 & 7 & 36.8 & 0 & 0.0 & & \\
\hline RBBB & 7 & 28.0 & 8 & 42.1 & 4 & 66.7 & 8.244 & 0.063 \\
\hline LBBB & 3 & 12.0 & 4 & 21.1 & 2 & 33.3 & & \\
\hline \multicolumn{9}{|l|}{ QRS Axis } \\
\hline $\mathrm{N}$ & 4 & 16.0 & 3 & 15.8 & 1 & 16.7 & & \\
\hline LF & 20 & 80.0 & 13 & 68.4 & 5 & 83.3 & 3.566 & 0.881 \\
\hline RT & 1 & 4.0 & 3 & 12.0 & 0 & 0.0 & & \\
\hline \multicolumn{9}{|l|}{ QRS width } \\
\hline \multicolumn{9}{|l|}{ Pre-pacing } \\
\hline Mean \pm SD & \multicolumn{2}{|c|}{$104.6 \pm 27.99$} & \multicolumn{2}{|c|}{$125.0 \pm 32.53$} & \multicolumn{2}{|c|}{$141.7 \pm 29.94$} & $7.848^{*}$ & $0.020^{*}$ \\
\hline \multicolumn{9}{|l|}{ Post-pacing } \\
\hline Mean \pm SD & \multicolumn{2}{|c|}{$148.6 \pm 22.98$} & \multicolumn{2}{|c|}{$154.2 \pm 19.46$} & \multicolumn{2}{|c|}{$156.7 \pm 26.58$} & 0.660 & 0.719 \\
\hline \multicolumn{9}{|l|}{ VP\% } \\
\hline 7 days & & & & & & & & \\
\hline Mean \pm SD & 83.40 & & 81.57 & & 97.0 & & 4.136 & 0.126 \\
\hline 6 months & & & & & & & & \\
\hline Mean \pm SD & 86.80 & & 89.11 & & 100.0 & & 3.848 & 0.146 \\
\hline Pacing threst & & & & & & & & \\
\hline 7 days & & & & & & & & \\
\hline Mean \pm SD & 0.57 & & 0.61 & & 0.46 & & 1.627 & 0.443 \\
\hline 6 months & & & & & & & & \\
\hline Mean \pm SD & 0.85 & & 0.92 & & 0.83 & & 0.184 & 0.912 \\
\hline
\end{tabular}


development of PICMP and PIVD before any reduction in EF develops. Pre-implantation QRS complex width may predict the development of PICMP and PIVD.

\section{Supplementary Information}

The online version contains supplementary material available at https://doi. org/10.1186/s43044-021-00136-x.

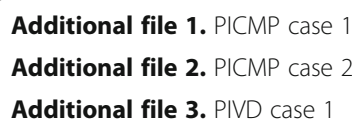

\section{Abbreviations}

COP: Cardiac output; EDV: End-diastolic volume; ESV: End-systolic volume; SV: Strove volume; GLS: Global longitudinal strain; LBBB: Left bundle branch block; RBBB: Right bundle branch block; LV: Left ventricle/ventricular; LVEF: Left ventricular ejection fraction; RV: Right ventricle/ventricular; PICMP: Pacing-induced cardiomyopathy; PIVD: Pacing-induced ventricular dysfunction; 3D: Three-dimensional; 2D: Two-dimensional; SSS: Sick sinus syndrome; ICD: Implantable cardioverter defibrillator; ECG: Electrocardiogram; IHD: Ischemic heart disease

\section{Acknowledgements}

To all the members of Cardiology Department at Alexandria Faculty of Medicine for their efforts in managing the case.

\section{Authors' contributions}

MD performed 3D echo and strain acquisitions at presentation and follow up visits. EE, MA, and MN performed the off-line data analysis. All authors shared in writing and approved the final manuscript.

\section{Funding}

This research did not receive any specific grant from funding agencies in the public, commercial, or not-for-profit sectors.

\section{Availability of data and materials}

The datasets used and/or analyzed during the current study are available from the corresponding author on reasonable request.

\section{Ethics approval and consent to participate}

The study was approved by Alexandria Faculty of Medicine ethics committee. The reference number is not applicable. All patients provided written informed consent

\section{Consent for publication}

All patients provided written informed consent.

\section{Competing interests}

All authors declare that they have no competing interests.

Received: 29 October 2020 Accepted: 13 January 2021

Published online: 26 January 2021

\section{References}

1. Wilkoff BL, Cook JR, Epstein AE, Greene HL, Hallstrom AP, Hsia H, Kutalek SP et al (2002) Dual-chamber pacing or ventricular backup pacing in patients with an implantable defibrillator: the Dual Chamber and WI Implantable Defibrillator (DAVID) Trial. Jama. 288(24):3115-3123

2. Steinberg JS, Fischer A, Wang P, Schuger C, Daubert J, Mcnitt S, Andrews M et al (2005) The clinical implications of cumulative right ventricular pacing in the multicenter automatic defibrillator trial II. J Cardiovasc Electrophysio 16(4):359-365

3. Prinzen FW, Peschar M (2002) Relation between the pacing induced sequence of activation and left ventricular pump function in animals. Pacing Clin Electrophysiol 25(4):484-498

4. Tse H-F, Lau C-P (1997) Long-term effect of right ventricular pacing on myocardial perfusion and function. J Am Coll Cardiol 29(4):744-749
5. Skalidis El, Kochiadakis GE, Koukouraki SI, Chrysostomakis SI, Igoumenidis NE, Karkavitsas NS, Vardas PE (2001) Myocardial perfusion in patients with permanent ventricular pacing and normal coronary arteries. J Am Coll Cardiol 37(1):124-129

6. Vernooy K, Dijkman B, Cheriex EC, Prinzen FW, Crijns HJ (2006) Ventricular remodeling during long-term right ventricular pacing following His bundle ablation. Am J Cardiol 97(8):1223-1227

7. Tops LF, Schalij MJ, Holman ER, van Erven L, van der Wall EE, Bax JJ (2006) Right ventricular pacing can induce ventricular dyssynchrony in patients with atrial fibrillation after atrioventricular node ablation. J Am Coll Cardiol 48(8):1642-1648

8. Sweeney MO, Hellkamp AS, Ellenbogen KA, Greenspon AJ, Freedman RA, Lee KL, Lamas GA (2003) Adverse effect of ventricular pacing on heart failure and atrial fibrillation among patients with normal baseline QRS duration in a clinical trial of pacemaker therapy for sinus node dysfunction. Circulation. 107(23):2932-2937

9. Schmidt M, Brömsen J, Herholz C, Adler K, Neff F, Kopf C, Block M (2007) Evidence of left ventricular dyssynchrony resulting from right ventricular pacing in patients with severely depressed left ventricular ejection fraction. Europace. 9(1):34-40

10. Akerström F, Arias MA, Pachón M, Jiménez-López J, Puchol A, Juliá-Calvo J (2013) The importance of avoiding unnecessary right ventricular pacing in clinical practice. World J Cardiol 5(11):410

11. Sweeney MO, Hellkamp AS (2006) Heart failure during cardiac pacing. Circulation. 113(17):2082-2088

12. Kaye GC, Linker NJ, Marwick TH, Pollock L, Graham L, Pouliot E, Poloniecki J et al (2014) Effect of right ventricular pacing lead site on left ventricular function in patients with high-grade atrioventricular block: results of the Protect-Pace study. Eur Heart J 36(14):856-862

13. Nikoo M, Ghaedian M, Kafi M, Jorat M, Fakhrpour A, Pakfetrat M, Ostovan M et al (2011) Effects of right ventricular septal versus apical pacing on plasma natriuretic peptide levels. J Cardiovasc Dis Res 2(2):104-109

14. Sulke N, Chambers J, Dritsas A, Sowton E (1991) A randomized double-blind crossover comparison of four rate-responsive pacing modes. J Am Coll Cardiol 17(3):696-706

15. Mehta D, Gilmour S, Ward DE, Camm AJ (1989) Optimal atrioventricular delay at rest and during exercise in patients with dual chamber pacemakers: a non-invasive assessment by continuous wave Doppler. Heart. 61(2):161-166

16. Wish M, Fletcher RD, Gottdiener JS, Cohen Al (1987) Importance of left atrial timing in the programming of dual-chamber pacemakers. Am J Cardiol 60(7):566-571

17. Dreger H, Maethner K, Bondke H, Baumann G, Melzer C (2011) Pacinginduced cardiomyopathy in patients with right ventricular stimulation for> 15 years. Europace. 14(2):238-242

18. Khurshid S, Epstein AE, Verdino RJ, Lin D, Goldberg LR, Marchlinski FE, Frankel DS (2014) Incidence and predictors of right ventricular pacinginduced cardiomyopathy. Heart Rhythm 11(9):1619-1625

19. Yu C-M, Chan JY-S, Zhang Q, Omar R, Yip GW-K, Hussin A, Fang F et al (2009) Biventricular pacing in patients with bradycardia and normal ejection fraction. N Engl J Med 361(22):2123-2134

20. Zhang XH, Chen H, Siu CW, Yiu KH, Chan WS, Lee KL, Chan HW et al (2008) New-onset heart failure after permanent right ventricular apical pacing in patients with acquired high-grade atrioventricular block and normal left ventricular function. J Cardiovasc Electrophysiol 19(2):136-141

21. Kiehl EL, Makki T, Kumar R, Gumber D, Kwon DH, Rickard JW, Kanj M et al (2016) Incidence and predictors of right ventricular pacing-induced cardiomyopathy in patients with complete atrioventricular block and preserved left ventricular systolic function. Heart Rhythm 13(12):2272-2278

22. Chan JY-S, Fang F, Zhang Q, Fung JW-H, Razali O, Azlan H, Lam K-H et al (2011) Biventricular pacing is superior to right ventricular pacing in bradycardia patients with preserved systolic function: 2-year results of the PACE trial. Eur Heart J 32(20):2533-2540

23. Ahmed FZ, Motwani M, Cunnington C, Kwok CS, Fullwood C, Oceandy D, Fitchet $A$ et al (2017) One-month global longitudinal strain identifies patients who will develop pacing-induced left ventricular dysfunction over time: the pacing and ventricular dysfunction (PAVD) study. PLoS One 12(1):e0162072

24. Babu NS, Srinath SC, Lahiri A, Chase D, John B, Roshan J (2018) Threedimensional echocardiography with left ventricular strain analyses helps earlier prediction of right ventricular pacing-induced cardiomyopathy. J Saudi Heart Assoc 30(2):102-107 
25. Delgado V, Tops LF, Trines SA, Zeppenfeld K, Marsan NA, Bertini M, Holman ER et al (2009) Acute effects of right ventricular apical pacing on left ventricular synchrony and mechanicsclinical perspective. Circ Arrhythm Electrophysiol 2(2):135-145

26. Ha S, Song Y, Lee W, Bang W, Yoo S, Cheong S (2017) P1676Global longitudinal strain improve prediction of right ventricular pacing induced left ventricular dyssynchrony in patients with permanent pacemaker. Eur Heart J 38(1):366

27. Kim S-H, Oh Y-S, Nam G-B, Choi K-J, Park JS, Park SW, Park S-J et al (2014) Paced QRS axis as a predictor of pacing-induced left ventricular dysfunction J Interv Card Electrophysiol 41(3):223-229

28. Khurshid S, Liang JJ, Owens A, Lin D, Schaller R, Epstein AE, Marchlinski FE et al (2016) Longer paced QRS duration is associated with increased prevalence of right ventricular pacing-induced cardiomyopathy. J Cardiovasc Electrophysiol 27(10):1174-1179

29. Toff WD, Camm AJ, Skehan JD (2005) Single-chamber versus dual-chamber pacing for high-grade atrioventricular block. N Engl J Med 353(2):145-155

\section{Publisher's Note}

Springer Nature remains neutral with regard to jurisdictional claims in published maps and institutional affiliations.

\section{Submit your manuscript to a SpringerOpen ${ }^{\circ}$ journal and benefit from:}

- Convenient online submission

- Rigorous peer review

- Open access: articles freely available online

High visibility within the field

- Retaining the copyright to your article

Submit your next manuscript at $\boldsymbol{\nabla}$ springeropen.com 